\title{
Idiopathic Neuropathy
}

National Cancer Institute

\section{Source}

National Cancer Institute. Idiopathic Neuropathy. NCI Thesaurus. Code C35098.

Neuropathy, the cause of which is not known. 